\title{
Scraped-Wounding Causes Activation and Association of C-Src Tyrosine Kinase with Microtubules in Cultured Keratinocytes
}

\author{
Takahiro Yamada $^{1}$, Yumi Aoyama ${ }^{1}$, M. Koji Owada ${ }^{*}$, Hisaaki Kawakatsu ${ }^{3}$, and Yasuo Kitajima \\ ${ }^{1}$ Department of Dermatology, Gifu University School of Medicine, Tsukasamachi 40, Gifu 500-8705, Japan \\ ${ }^{2}$ Institute of Molecular and Cell Biology for Pharmaceutical Sciences, Kyoto Pharmaceutical University, \\ Shichono-cho 1, Misasagi, Yamashina-ku, Kyoto 607-8412, Japan, and ${ }^{3}$ The Lung Biology Center, Uni- \\ versity of California, Box 0854, San Francisco, CA 94143, USA
}

\begin{abstract}
$A B S T R A C T$. In order to elucidate the function of c-Src in keratinocytes, we studied the intracellular distribution of its active and inactive form in cultured normal human keratinocyte, using anti-c-Src monoclonal antibody clone 28, which recognizes the active form of c-Src (dephosphorylated at COOH-terminal residue Tyr 530), and monoclonal antibody clone 327 which recognizes both active and inactive forms. Since c-Src has been suggested to be involved in the control of cell adhesion in other cells, we produced a dynamic condition of cell migration by cutting culture cell colonies into squares to form a mesh pattern with a blade (culture wound model). Before cutting, the active form was expressed in cells located only at the periphery of colonies or isolated migrating cells, and was associated with microtubules. Wounding the colony generated a dramatic and rapid activation of c-Src in a few rows of cells along the cut edges, which were made even at the middle of colony, resulting in the association of the active form with microtubules. This increase of the active form was also detected by immunoblotting of cell extracts. These reactions were inhibited by $1 \mathrm{mM}$ sodium orthovanadate, a protein-tyrosine phosphatase inhibitor. ST 638, a potent Src family tyrosine kinase inhibitor, inhibited the migration of keratinocytes in the culture wound healing model. These results suggest that wounding the culture causes activation of c-Src in keratinocytes, and thus activated c-Src may play a role in the function of microtubules during cell migration, especially at an early stage of wound healing.
\end{abstract}

Key words: c-Src/keratinocyte/wound healing/microtubules

During wound healing, keratinocytes (KCs) must dynamically regulate cell-cell contacts and cytoskeletons in order to migrate to and cover the surface of the wound. Major cell-cell contacts between KCs are adherens junctions and desmosomes, the former of which are specifically associated with actin microfilaments and the latter with keratin-intermediate filaments. The intercellular contacts of adherens junctions are mediated in a homotypic manner with Ecadherin (Takeichi, 1991), and linked to actin filaments via vinculin, $\alpha$-actinin, $\alpha$-catenin, $\beta$-catenin, plakoglobin and P120-Cas (Kam et al., 1995; Tsukita et al., 1992; Reynolds

\footnotetext{
* To whom correspondence should be addressed: Institute of Molecular and Cell Biology for Pharmaceutical Sciences, Kyoto Pharmaceutical Univertisy, Shichono-cho 1, Misasagi, Yamashina-ku, Kyoto 607-8412, Japan.

Tel: $+81-75-595-4716, \quad$ Fax: $+81-75-595-4790$

E-mail: owada@mb.kyoto-phu.ac.jp

Abbreviations: KC, keratinocyte; mAb, monoclonal antibody; TX, Triton X-100.
}

et al., 1992, 1994, 1996). Increase in tyrosine phosphorylation of $\beta$-catenin, plakoglobin and P120-Cas, which are known as substrate of c-Src, has been shown to be correlated with decrease of cell adhesion, which is one of the typical characteristics of neoplastic transformation (Matsuyoshi et al., 1992; Behrens et al., 1993; Hamaguchi et al., 1993; Papkoff, 1997). The regulation of cell-cell contacts is thought to be one of the most important events for KCs to cover the wound surface (Grinnell, 1990), and the following differentiation. Therefore, it is of potential importance to clarify the intracellular signaling mechanisms involved in wound healing in skin.

Src is a non receptor type tyrosine kinase, which is widely expressed (Bolen et al., 1992) including KCs (Zhao et al., 1992), and are thought to play a critical role in regulation of cell growth (Weissman and Aaronson, 1985), tissue development (Levy et al., 1984; Gessler and Barnekow, 1984) and cell migration (Mureebe et al., 1997; LaVallee et al., 
1998). Regarding intracellular localization, c-Src has been known to localize mostly in association with plasma membranes (Willingham et al., 1979; Resh and Erikson, 1985), whereas v-Src interacts with non ionic detergent-insoluble cellular matrix (Loeb et al., 1987; Krueger et al., 1991).

In KCs, tyrosine phosphorylation and Src family kinase activation have been shown to control the KC cell-cell adhesion (Hamaguchi and Hanafusa, 1987; Calautti et al., 1998) and differentiation (Zhao et al., 1992). During wound healing, KCs must laterally migrate to cover the wound surface and proliferate followed by differentiation to reconstruct the epidermis. These processes are associated with dynamic regulation of contacts with the extracellular matrix, i.e., hemidesmosomes and focal contacts, and adherens junctions. Dynamic rearrangements of the cytoskeletons of microfilaments and microtubules are thought to be also profoundly involved in cell migration in vitro at the earliest phase of wound healing (Gordon and Staley, 1990; Gordon and Buxar, 1997; Nakamura et al., 1991, Ettenson and Gotlieb, 1992; Baschong et al., 1997).

Src family tyrosine kinases have been known to phosphorylate adherens junction associated proteins, i.e., $\beta$ - and $\alpha$ catenins, plakoglobin and p120 Cas, and to decrease their binding affinity to E-cadherin in neoplastic cells (Papkoff, 1997; Kinch et al., 1995), and mitogenic growth factor stimulated cells (Miller and Moon, 1996)

In this study, we analyzed biochemically and immunocytochemically the mode of activation and translocation of cSrc in culture wound healing model of normal human KCs by using monoclonal antibody (mAb) 327 specific to c-Src and $\mathrm{mAb}$ clone 28 , which selectively recognizes the active form of c-Src dephosphorylated at C-terminal Tyr 530 (Kawakatsu et al., 1996), in order to elucidate the function of the activated c-Src in KCs during wound healing. Sensitivity and usefulness of clone 28 to detect low amounts of activated c-Src in vivo and in vitro has been reported recently (Kawakatsu et al., 1996; Sakai et al., 1998; Luttrel et al., 1999).

\section{Materials and Methods}

\section{Antibodies and reagents}

Clone 28, which was previously shown to specifically recognize the active form of c-Src (Kawakatsu et al., 1996), and monoclonal antibody mAb 327 (CALBIOCHEM-NOVABIOCHEM Co., La Jolla, CA, USA), which reacts with both active and inactive forms of c-Src tyrosine kinase, were used in this study. Anti-tubulin antibody (clone YL1/2) was purchased from Harlan Sera-Lab Ltd. (Loughborough, England). Fluorophore conjugated affinity purified secondary antibodies were purchased from ICN Pharmaceuticals Inc. (Aurora, OH, USA). Horseradish peroxidase conjugated secondary antibodies were purchased from Amersham International Plc (Buckinghamshire, UK). Triton X-100 (TX), phenylmethylsulfonyl fluoride (PMSF), N-tosyl-L-phenylalanine chloromethyl ketone (TPCK), and trans-epoxysuccinyl-L-leucylamido-butane (E-64) were purchased from SIGMA chemical Co. (St. Lois, MO, USA). Paraformaldehyde was purchased from Nacalai Tesque Inc. (Kyoto, Japan). Other chemicals were purchased from Wako Pure Chemical Industries, Ltd. (Osaka, Japan)

\section{Cells}

Normal human KCs were obtained from normal individuals (ages 30-50) and cultured in Keratinocyte-SFM medium (Life Technologies, Inc., Rockville, MD, USA). DJM-1 cells, a human squamous cell carcinoma cell line (Kitajima et al., 1986, 1987), were cultured in s-MEM (Life Technologies, Inc.) supplemented with $10 \%(\mathrm{v} / \mathrm{v}) \mathrm{Ca}^{2+}$-chelated fetal bovine serum (IS-Japan, Tokyo, Japan), $84 \mathrm{ng} / \mathrm{ml}$ choleratoxin (Life Technologies, Inc.) and $0.4 \mu \mathrm{g} /$ $\mathrm{ml}$ hydrocortisone (Sigma) and $\mathrm{CaCl}_{2}$ (the final $\mathrm{Ca}^{2+}$ concentration of the medium was adjusted to $0.09 \mathrm{mM}$ ). Cells were cultured on $24 \times 24 \mathrm{~mm}$ glass coverslips (Matsunami Glass Co. Tokyo, Japan) for immunofluorescent microscopy in $35 \mathrm{~mm}$ cell culture dishes (Becton-Dickinson and Co., Franklin Lakes, NJ, USA) and 100 mm cell culture dishes (Corning Costar Corp., Cambridge, MA, USA) for biochemical study in $37^{\circ} \mathrm{C} \mathrm{CO}_{2}$-incubator.

\section{Wound healing model}

We produced a dynamic condition of in vitro wound healing model by cutting the cultured cell colonies. After cells reached confluency on glass coverslips or culture dishes, linear wounds were made in the KCs colonies by cutting with a $200 \mu$ lyellow pipette chip (Greiner GmbH, Frickenhausen, Germany). Before and 30 min after wounding the culture, cells grown on the glass coverslips were subjected to immunofluorescent microscopy and cells grown on culture dishes were used for immunoblotting studies.

\section{Indirect immunofluorescence}

Cells cultured on glass coverslips were fixed with $3 \%$ phosphatebuffered paraformaldehyde. The fixed cells were rinsed with $\mathrm{pH}$ 7.4 phosphate buffered saline (PBS) and permeabilized by $0.05 \%$ TX in PBS. Cells were then rinsed with PBS and incubated with relevant primary antibodies for $2 \mathrm{~h}$ at room temperature, washed 5 times with PBS and incubated with the fluorophere conjugated secondary antibodies at a dilution 1:40. Stained cells on the glass coverslips were mounted in FluorSave ${ }^{\mathrm{TM}}$ Reagent (CALBIOCHEM-NOVABIOCHEM Co.) and examined with a fluorescent microscope, Microphot FXA (Nikon Co., Tokyo, Japan) or confocal laser microscopy MRC-1000 (Bio-Rad Laboratories, Hercules, CA, USA).

\section{Preparation of lysates from culture cells}

After cells grown on culture dishes were rinsed with PBS, they were harvested by using cell scraper (Becton-Dickinson Co.) in the presence of protein-tyrosine phosphatase inhibitor $(2 \mathrm{mM}$ sodium orthovanadate) and protease inhibitors (1 $\mathrm{mM}$ PMSF, $1 \mathrm{mM}$ TPCK, and $1 \mu \mathrm{M}$ E-64). Cell suspensions were homogenized 3 times for 10 sec each by ultrasonic homogenizer UR-200P (TOMY 
Seiko Co., Tokyo, Japan) at $0^{\circ} \mathrm{C}$. The homogenates were centrifuged at $100,000 \times g$ for $60 \mathrm{~min}$ and the resultant supernatants were recovered as the cytosol fraction and the pellets were rehomogenized with PBS containing $0.5 \%(\mathrm{w} / \mathrm{v}) \mathrm{TX}$ and centrifuged at $100,000 \times g$ for $60 \mathrm{~min}$. The resultant supernatants were recovered as the TX soluble fraction and the resulting pellets were resuspended and analyzed as the cytoskeleton fraction. These processes were performed in the presence of phosphatase and protease inhibitors as indicated. After protein concentration assay was carried out by BCA protein assay kit (Pierce, Rockford, IL, USA), the samples were mixed with sample buffer $(0.25 \mathrm{M}$ Tris- $\mathrm{HCl}, \mathrm{pH} 6.8,2 \%$ SDS, $10 \%$ (w/v) 2-mercaptoethanol, 30\% glycerol, distilled water) and boiled at $97^{\circ} \mathrm{C}$ for $5 \mathrm{~min}$ followed by electrophoresis.

\section{Western blotting}

Equal amounts of protein $(25 \mu \mathrm{g})$ were applied to each lane. After SDS-polyacrylamide gel electrophoresis (SDS-PAGE), proteins were transferred onto a nitrocellulose membrane (Amersham International Plc) by means of semidry blotting system (Bio-Rad Laboratories) at a constant voltage of $10 \mathrm{~V}$ for $30 \mathrm{~min}$. Blocking was performed in a $0.01 \mathrm{M}$ PBS (pH 7.4) with $0.1 \%(\mathrm{w} / \mathrm{v})$ Tween 20 and $5 \%$ biochemical grade skim milk. After incubation with relevant primary antibodies, the membranes were then reacted with horseradish peroxidase-conjugated secondary antibodies at a dilution of 1:3000. The signal was developed on Hyperfilm ECL ${ }^{\text {TM }}$ with Enhanced Chemiluminescence (ECL ${ }^{\mathrm{TM}}$ ) system (Amersham International Plc). If necessary, developed films were scanned by image scanner GT-6500ART (SEIKO-EPSON Co., Nagano, Japan) and saved as not-compressed tagged image file format (TIFF). We processed these image files by using NIH image version 1.58 .

\section{Immunoprecipitation}

Cells were scraped from dishes in the presence of digitonin lysis buffer (1\% digitonin, $10 \mathrm{mM}$ triethanolamine, $150 \mathrm{mM} \mathrm{NaCl}, 10$ mM iodoacetamide, $1 \mathrm{mM}$ EDTA, $10 \mu \mathrm{g} / \mathrm{ml}$ aprotinin, $1 \mathrm{mM}$ 4-(2aminoethyl) benzenesulfonylfluoride (AEBSF), pH 7.8) (AbuAmer et al., 1997; Bridges, 1977) and incubated at $37^{\circ} \mathrm{C}$ with gentle rocking for $30 \mathrm{~min}$. Cell suspensions were passed through a 26gauge needle 10 times and centrifuged at $10,000 \mathrm{rpm}$ for $10 \mathrm{~min}$. The supernatants of lysates were precleared with excess of Protein A-Sepharose or Protein G-Sepharose (Pharmacia LKB Biotechnology Inc, Piscataway, NJ) and incubated for $2 \mathrm{~h}$ with relevant antibodies followed by Protein A or G beads. The beads containing immunecomplexes were washed with lysis buffer and boiled for 5 min in SDS sample buffer (as described above). The samples were centrifuged at 10,000 rpm for $3 \mathrm{~min}$ and the resultant supernatants were subjected to electrophoresis on SDS-PAGE and Western blotting.

\section{Assay of wound healing capacity}

Confluent cultures were wounded by manual scratching with a cell scraper. Wounded cultures were washed with PBS and treated with
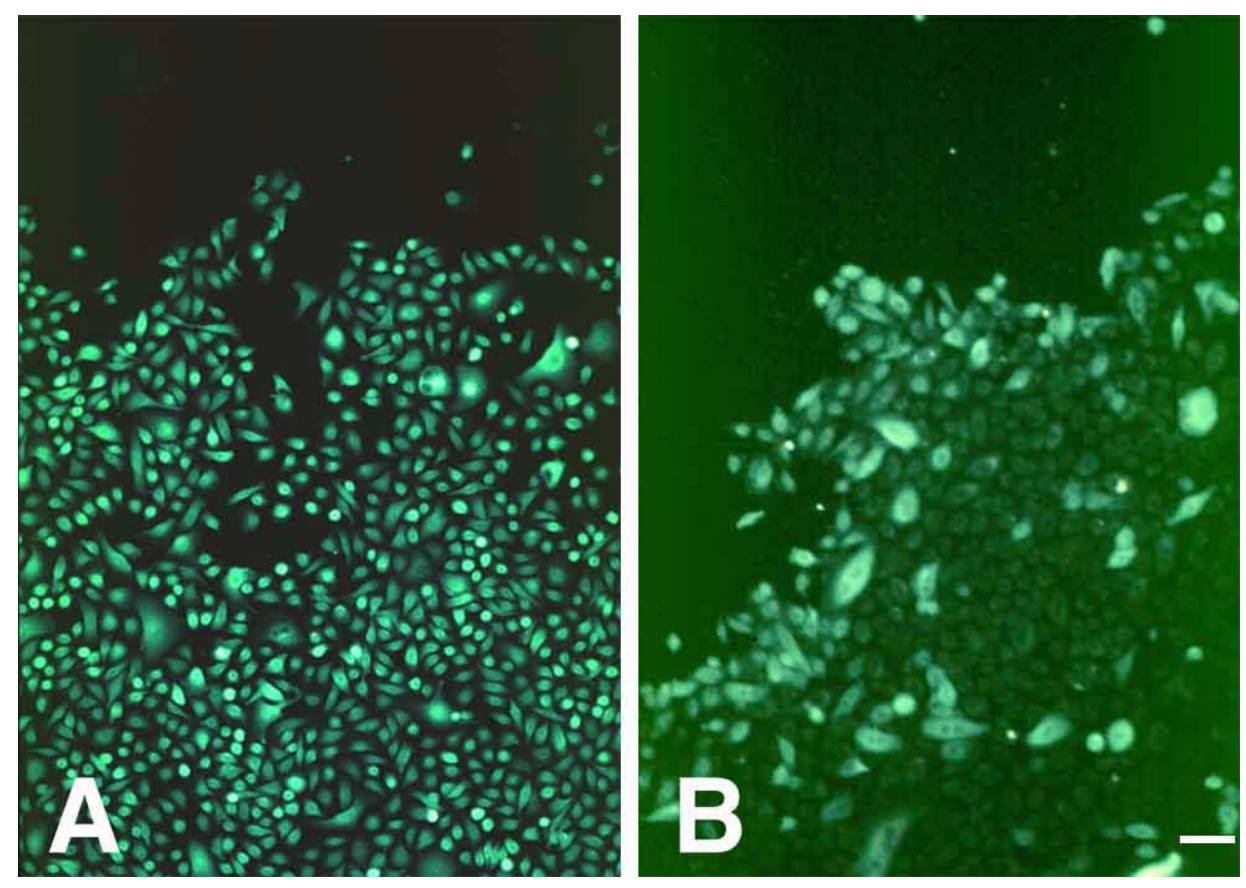

Fig. 1. Localization of the active form of c-Src in the colony of normal human KCs. Colonies of KCs formed on the glass coverslips were immunostained with $\mathrm{mAb} 327$ for active and inactive form (A) or clone 28 specific for active form of (B) and subsequently with FITC-labeled anti-mouse secondary antibody. Active form of c-Src localized at the edge of the colony (B), whereas c-Src localized in the center of the colony (A). Bar, $150 \mu \mathrm{m}$. 
$10 \mu \mathrm{g} / \mathrm{ml}$ mitomycin $\mathrm{C}$ for $2 \mathrm{~h}$, and then incubated with or without $50 \mu \mathrm{M} \alpha$-cyano-3-ethoxy-4-hydroxy-5-phenylthiomethycinnamamide (ST 638), tyrosine kinase inhibitor (Shiraishi et al., 1987, 1989) and the wound repairing time was observed. After the wound of control culture was repaired, the culture containing ST 638 was washed free of the drug and further cultivated to observe the wound repairing time.

\section{Results}

\section{Localization of the active form of c-Src in the pe- ripheral cells of large colonies of human KC culture}

Immunofluorescent microscopy showed that c-Src stained by mAb 327 was distributed in nearly all cells throughout the colony of KC (Fig. 1A), whereas the active form of cSrc stained by clone 28 was distributed only in the peripheral cells, but not in the center of colonies (Fig. 1B). This observation was specially clearer in large colonies than in small colonies (data not shown). Treatment with $1 \mathrm{mM}$ sodium orthovanadate (an inhibitor of protein-tyrosine phosphatase) for $60 \mathrm{~min}$, abolished the detection of the active form of c-Src from the peripheral cells of large colonies (data not shown), suggesting that dephosphorylation of c-Src at C-teminal Tyr-530 is important.

\section{Intracellular localization and association of the active form of c-Src with microtubules}

By immunofluorescent microscopy, c-Src was detected diffusely by $\mathrm{mAb} 327$ in the cytoplasm with a denser localization at the juxtanuclear zone (Fig. 2A). The active form of c-Src, however, illustrated a microtubular pattern in cytoplasm (Fig. 2B). This pattern, therefore, was examined by double staining immunofluorescent microscopy using antibodies against tubulin and clone 28 . The results showed an almost identical fibrillar pattern indicating the association between microtubules and the active form of c-Src (Fig. $3)$. To confirm this association biochemically, immunoprecipitation with clone $28, \mathrm{mAb} 327$ and anti-tubulin antibody followed by immunoblotting with each antibody was performed. The mAb 327- or clone 28-immunoblotting of antitubulin immunoprecipitates showed co-immunoprecipitation of c-Src/the active form of c-Src and tubulin. On the other hand, anti-tubulin-immunoblotting of mAb 327-immunoprecipitates also showed co-immunoprecipitation of tubulin with c-Src/the active form of c-Src (Fig. 4). These results indicate the association of the active form of $\mathrm{c}-\mathrm{Src}$ with microtubules in cultured human $\mathrm{KC}$.

\section{Subcellular distribution of the active form of c-Src}

As examined by immunoblotting of extracts from subcellular fractions, c-Src recognized by mAb 327 was distributed mainly in the TX soluble fraction, with only small amounts in cytoskeleton fraction and cytosol fraction (Fig. 5 right

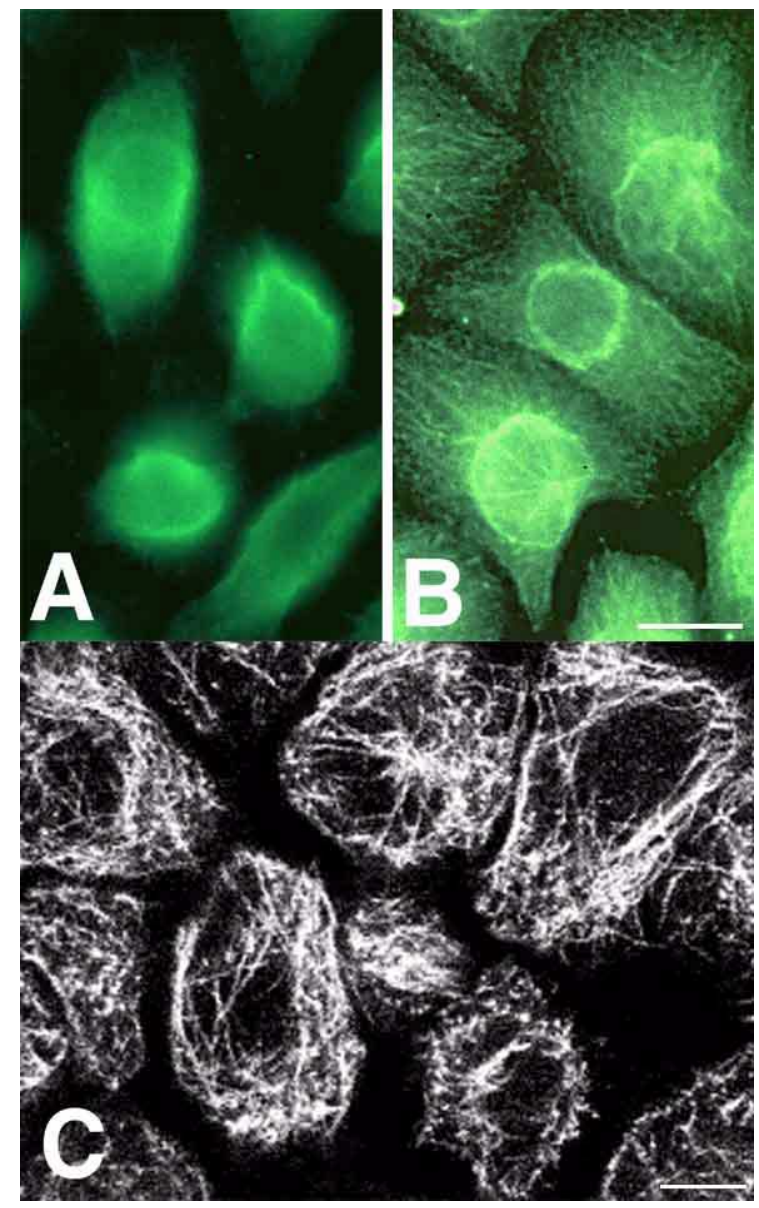

Fig. 2. Intracellular localization of c-Src and the active form of c-Src. Fixed cells were immunostained with mAb 327:anti c-Src (A) or clone 28:anti active form (B, C) and subsequently with FITC-labeled anti-mouse secondary antibody. Active form of c-Src showed cytoskeletal or fibrillar pattern (B, C), but c-Src did not (A). C: Stained cells were observed by a confocal laser microscopy, showing distinct fibrous distribution of the active form of c-Src. The different appearances of the microtubles between $\mathrm{B}$ and $\mathrm{C}$ is due to the fact that $\mathrm{C}$ represents a single-cut focal plane of individual cells, whereas B is the total accumulated focal planes of the cells. Bar, $10 \mu \mathrm{m}$.

panel). In contrast, the active form of c-Src was more enriched in cytoskeleton fraction than TX soluble fraction (Fig. 5 left panel).

\section{C-Src is activated in cells at colony cut edges immedi- ately after wounding}

In order to examine whether activation of c-Src is caused in association with cell migration, colonies of $\mathrm{KCs}$ were cut and observed by immunofluorescence microscopy after staining with clone 28 . In a few rows of colony cells at cut edges, the activated c-Src was detected 30 min after wounding the colony and this activation lasted more than $24 \mathrm{~h}$ (Fig. 6A). Interestingly, this activation was inhibited with 1 mM sodium orthovanadate (Fig. 6B). 

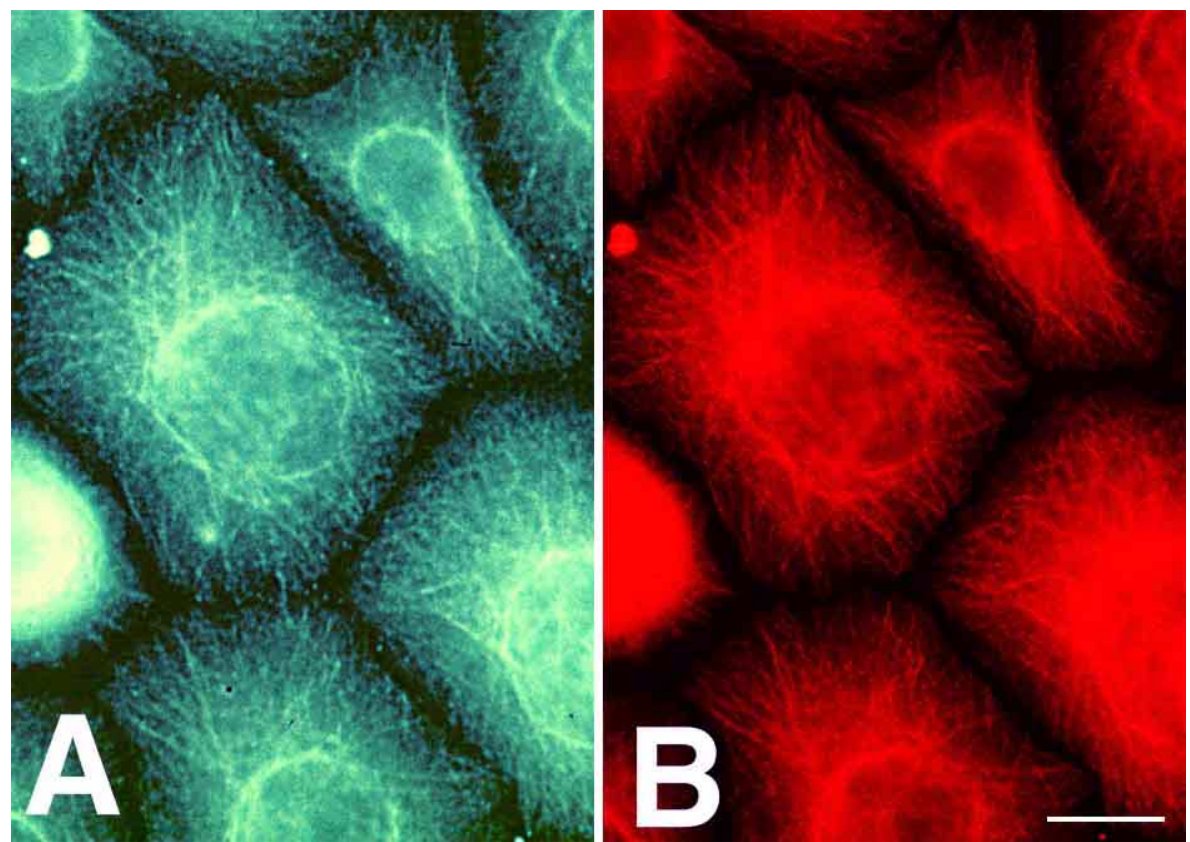

Fig. 3. Association between microtubules and the active form of c-Src. Fixed cells were double-stained with clone 28 (A) and anti-tubulin antibody (YL1/2) (B) and subsequently with FITC-labeled anti-mouse secondary antibody and rhodamine-labeled anti-rat secondary antibody, respectively. The active form of c-Src and microtubules appear to co-localize, showing a fibrillar pattern. Bar, $10 \mu \mathrm{m}$.

\section{Wounding the colony elevated the activated form of c-Src both in TX soluble and insoluble fractions}

Since immunofluorescence microscopy revealed that multiple linear woundings caused activation of c-Src at cut edges, we confirmed this activation biochemically by immunoblotting of samples obtained after fractionation with clone 28 and $\mathrm{mAb} 327$. The active form of $\mathrm{c}-\mathrm{Src}$ increased significantly after wounding the colony, while the total amount of c-Src did not, suggesting the preexisting inactive c-Src was activated (Fig. 7A). The active-form increased 2-fold in TX soluble fraction and 1.5-fold in cytoskeleton fraction. (Fig. 7B)

\section{ST 638 inhibits wound healing in cultured wound model}

To examine whether tyrosine kinase activity of c-Src was required for wound healing, a potent Src family tyrosine kinase inhibitor, $50 \mu \mathrm{m}$ ST 638 was introduced in the wound cultured cells. Wound healing was not significantly affected with mitomycin $\mathrm{C}$, which inhibits cell proliferation (data not shown). Healing time after scraping the culture was $120 \mathrm{~h}$ (Fig. 8). When cultures were incubated with ST 638 , healing had not taken place even $120 \mathrm{~h}$ after wounding, suggesting that tyrosine kinase activity is required to heal the wound. It should be also noted that the removal of ST 638 from the culture medium all over the cultures to heal the wounds within $48 \mathrm{~h}$ (Fig. 8). This suggests that treat- ment with ST 638 did not exert cytotoxic effects to kill the cells.

\section{Discussion}

Data presented in this paper indicate that c-Src was activated only in the peripheral cells of the KC colony and that the activated c-Src was associated with microtubules, whereas non-active c-Src was distributed throughout the colony of $\mathrm{KCs}$ and diffusely in the cytosol. These results suggest that c-Src phosphorylates the proteins associated with microtubules or tubulin itself, and peripheral cells of the KC colony need the active form of c-Src and the phosphorylation of some proteins associated with microtubules. Although the mechanism of c-Src activation and the substrate of the activated c-Src have yet to be clearly elucidated, c-Src/microtubules association has been also observed in osteoclast precursor upon adherence to specific extracellular matrix (Abu-Amer et al., 1997). A member of Src family tyrosine kinases, Fyn/microtubules association and phosphorylation of tubulin have been also reported in human $\mathrm{T}$ cell activation (Marie-Cardine et al., 1995) and monocytic differentiation (Katagiri et al., 1993). In this regard it is of interest to note that although rearrangement of both microfilaments and microtubules is an important event during wound healing, the rearrangement of microtubules is more important at the beginning of cell migration during in vitro wound healing (Gordon and Staley, 1990; Gordon and Buxar, 


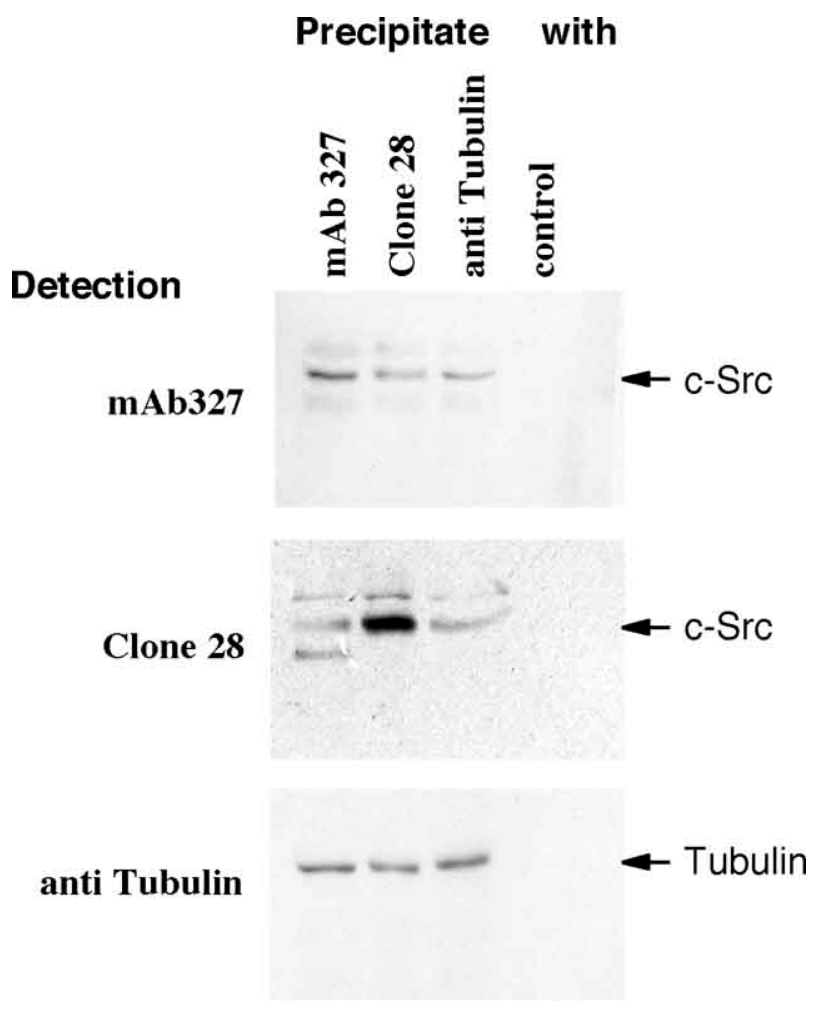

Fig. 4. Co-precipitation of tubulin and the active form of c-Src Immunorecipitates of clone $28, \mathrm{mAb} 327$, anti-tubulin antibody and normal mouse IgG were applied to each lane and detected by antibodies shown in the figure. Immunoprecipitate with clone 28 contains the active form Src and tubulin. Conversely, immunoprecipitate with anti-tubulin antibody contains the active form of Src. Immunoprecipitate with normal mouse IgG did not contain c-Src, active form c-Src or tubulin.

Clone 28

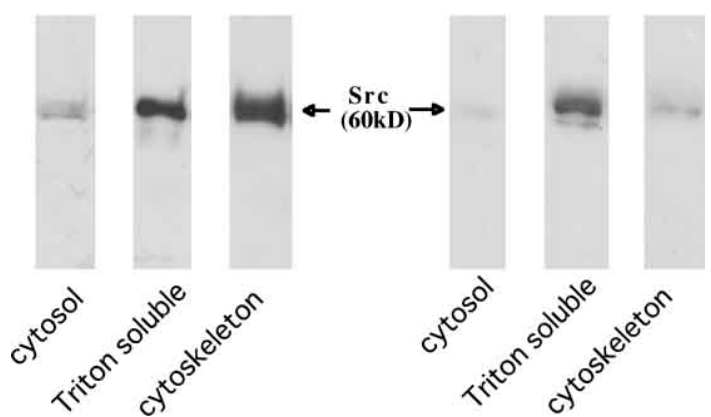

Fig. 5. Subcellular distribution of the active form of c-Src. Cells were lysed and fractionated as described in Materials and Methods. Proteins (25 $\mu \mathrm{g})$ were analyzed by SDS-PAGE and immunoblotted by mAb 327 and clone 28. C-Src distributes mainly in the TX soluble fraction. In contrast, the active form of c-Src is enriched more in the cytoskeleton fraction than in the TX soluble fraction.
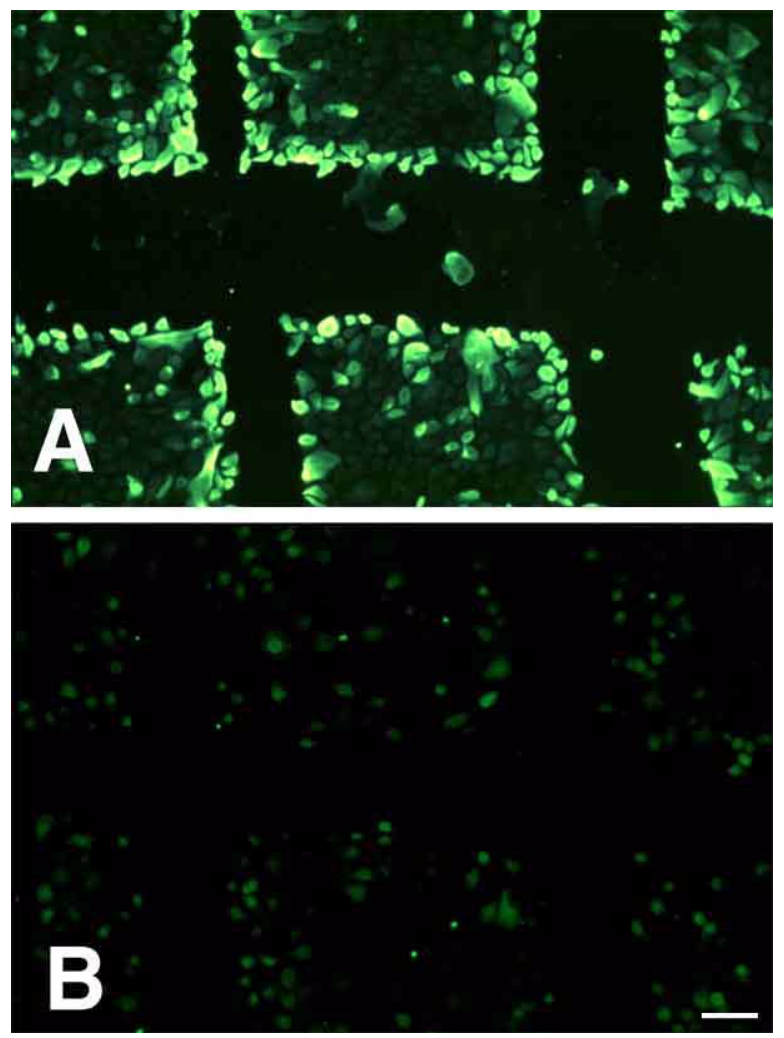

Fig. 6. Activation of c-Src at colony cut edges. Cut colonies were incubated for $30 \mathrm{~min}$ and immunostained with clone 28 (A). Cut colonies were also incubated in the presence of $1 \mathrm{mM}$ sodium orthovanadate for $30 \mathrm{~min}$ and immunostained (B). Activated c-Src was found remarkably at the wound edges of the colony. Bar, $150 \mu \mathrm{m}$

1997; Nakamura et al., 1991, Ettenson and Gotlieb, 1992; Baschong et al., 1997).

It is of great interest to note that the peripheral cells of the colony naturally or physiologically activate c-Src, leading to its association with microtubules. Since c-Src was active only in the peripheral KCs of colony, and these peripheral cells are thought to have a higher cellular activity in migration, we designed a culture wound healing model in which cells are activated in proliferation and migration similar to the peripheral cells. In this experimental model, colony wounding of static $\mathrm{KCs}$, which are located in the center of the colony and where c-Src was inactive, induced activation of c-Src and binding of the activated c-Src with microtubules, associated with cell-migration and healing the wound of the colony.

Since both cell migration and proliferation are important factors in wound healing, in order to determine whether the role of the active form of $\mathrm{c}-\mathrm{Src}$ is in proliferation or migration in the peripheral cells of KC colony and the cells at cut edges of colony wound, we examined the wound healing capacity in the presence or absence of tyrosine kinase inhibitor ST 638 and mitomycin C, an inhibitor of proliferation. 

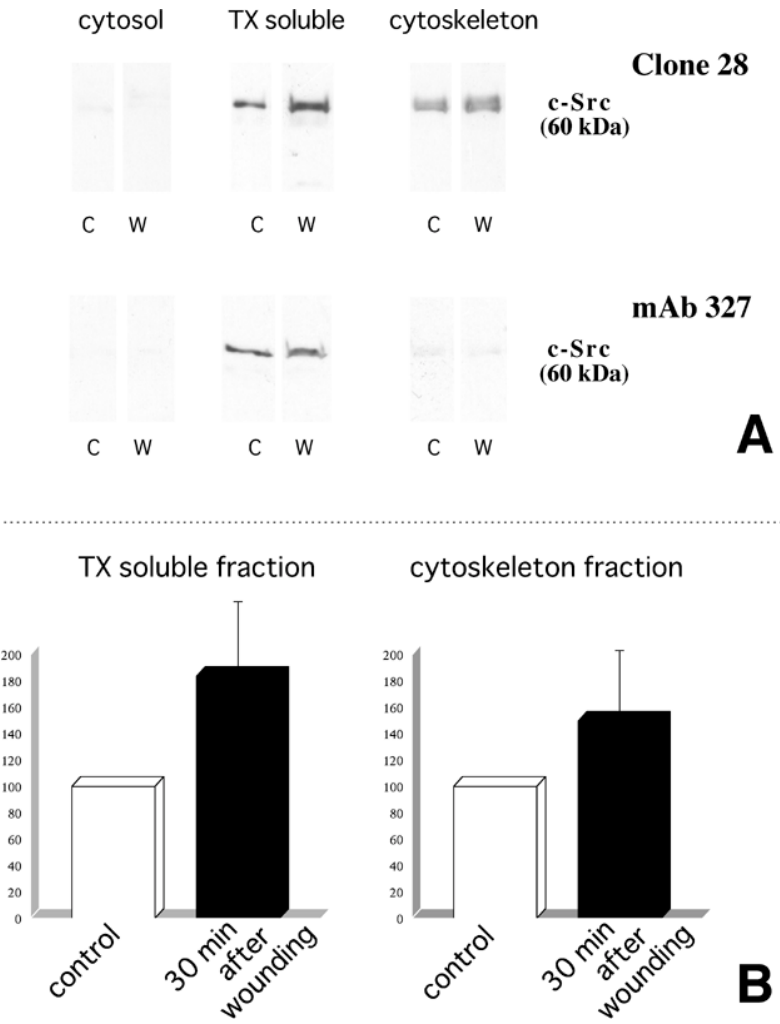

cytoskeleton fraction

Fig. 7. Wounding the colony elevated activated c-Src in TX soluble and insoluble fractions. Cut colonies were incubated for $30 \mathrm{~min}$ and cells were lysed and fractionated as described in Materials and Methods. Proteins (25 $\mu \mathrm{g}$ ) were applied to each lane and detected by $\mathrm{mAb} 327$ and clone 28 (A). Immunoblots were scanned by imagescanner and analyzed by NIH image (v1.58) as described in Materials and Methods. Shown is the mean \pm standard deviation of triplicates from the three independent experiments (B). Activated c-Src increased significantly both in TX soluble and insoluble fraction 30 min after wounding the colony. In contrast, total amounts of c-Src show no change. C: control, W: wounded.

ST 638 is a potent inhibitor for c-Src family kinases, though it also inhibits EGF receptor kinase (Shiraishi et al., 1987, 1989, 1990). ST 638 prevented the cells from wound healing. However, after the removing ST 638, the wound healing capacity was rapidly recovered, suggesting that the activation of c-Src kinase may be involved in at the early phase of wound healing, especially in the cell migration to heal wound, because mitomycin $\mathrm{C}$ exerted no effects on this migration. These findings suggest that activation of c-Src mediates $\mathrm{KC}$ migration during wound healing at wound edge.

Recent genetic study with skin of mice of double knockout mutations of Src and Fyn genes demonstrated that tyrosine phosphorylation by Src family kinases regulate $\mathrm{KC}$ differentiation (Calautti et al., 1998). Important questions remain as to how cutting or wounding activates c-Src in cultured KC colony and how its activation and association with microtubules signals downwards.
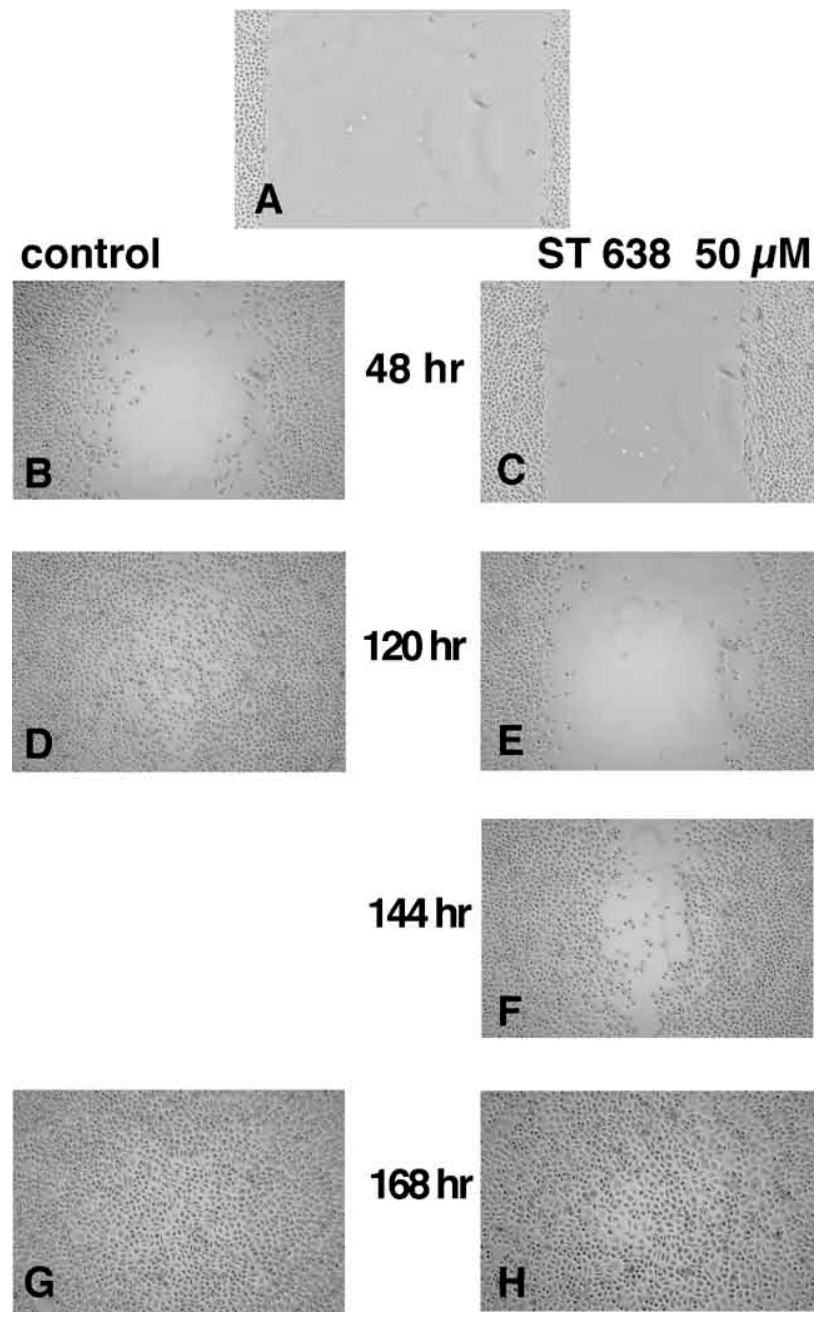

Fig. 8. ST 638, a tyrosine kinase inhibitor, inhibits wound healing capacity in cultured wound model. Confluent colonies were wounded as described in Materials and Methods. Wounded colonies were incubated with $(\mathrm{C}, \mathrm{E})$ or without $(\mathrm{B}, \mathrm{D}) 50 \mu \mathrm{M} \mathrm{ST} 638$. At $120 \mathrm{~h}$ later, ST 638-treated cells were washed well and further incubated for $24 \mathrm{~h}(\mathrm{~F})$ and $48 \mathrm{~h}(\mathrm{H})$ without ST638. Control culture of $168 \mathrm{~h}(\mathrm{G})$. ST638 inhibited wound healing of the colony.

Acknowledgments. We thank Fumiko Nomura and Yuki Tsujimura for technical assistance. This work was supported by grants from the Scientific Research Fund of the Ministry of Education, Science, and Culture, Japan, and by grants from the Ministry of Health and Welfare, Japan.

\section{References}

Abu-Amer, Y., Ross, F.P., Schlesinger, P., Tondravi, M.M., and Teitelbaum, S.L. 1997. Substrate recognition by osteoclast precursors induces C-src/Microtubule association. J. Cell Biol., 137: 247-258.

Baschong, W., Sutterlin, R., and Aebi, U. 1997. Punch-wounded, fibroblast populated collagen matrices: a novel approach for studying cytoskeletal changes in three dimensions by confocal laser scanning microscopy. Eur. J. Cell Biol., 72: 189-201.

Behrens, J., Vakaet, L., Friis, R., Winterhager, E., VanRoy, F., Mareel, M. 
M., and Birchmeier, W. 1993. Loss of epithelial differentiation and gain of invasiveness correlates with tyrosine phosphorylation of the Ecadherin/ $\beta$-catenin complex in cells transformed with a temperature-sensitive v-SRC gene. J. Cell Biol., 120: 757-766.

Bolen, J.B., Rowley, R.B., Spana, C., and Tsygankov, A.Y. 1992. The Src family of tyrosine protein kinases in hemopoietic signal transduction. FASEB J., 6: 3403-3409.

Bridges, C.D.B. 1977. A method for preparing stable digitonin solutions for visual pigment extraction. Vision Res., 17: 301-302.

Calautti, E., Cabodi, S., Stein, P.L., Hatzfeld, M., Kedersha, N., and Dotto, G.P. 1998. Tyrosine phosphorylation and src family kinases control keratinocyte cell-cell adhesion. J. Cell Biol., 141: 1449-1465.

Ettenson, D.S. and Gotlieb, A.I. 1992. Centrosomes, microtubules, and microfilaments in the reendothelialization and remodeling of double-sided in vitro wounds. Lab. Invest., 66: 722-733.

Gessler, M. and Barnekow, A. 1984. Differential expression of the cellular oncogenes c-src and c-yes in embryonal and adult chicken tissues. Biosci. Rep., 4: 757-770.

Gordon, S.R. and Staley, C.A. 1990. Role of the cytoskeleton during injury-induced cell migration in corneal endothelium. Cell Motil. Cytoskeleton, 16: 47-57.

Gordon, S.R. and Buxar, R.M. 1997. Inhibition of cytoskeletal reorganization stimulates actin and tubulin syntheses during injury-induced cell migration in the corneal endothelium. J. Cell Biochem., 67: 409-421.

Grinnell, F. 1990. The activated keratinocyte: Up regulation of cell adhesion and migration during wound healing. J. Trauma, 30: S144-149.

Hamaguchi, M. and Hanafusa, H. 1987. Association of pp60src with Triton X-100 resistent cellular structure correlates with morphological transformation. Proc. Natl. Acad. Sci. USA, 84: 2312-2316.

Hamaguchi, M., Matsuyoshi, N., Ohnishi, Y., Gotoh, B., Takeichi, M., and Nagai, Y. 1993. p60v-src causes tyrosine phosphorylation and inactivation of the N-cadherin-catenin cell adhesion system. EMBO J., 12: 307314.

Kam, Z.,Volberg, T., and Geiger, B. 1995. Mapping of adherens junction components using microscopic resonance energy transfer imaging. $J$. Cell Sci., 108: 1051-1062.

Katagiri, K., Katagiri, T., Kajiyama, K., Yamamoto, T., and Yoshida, T. 1993. Tyrosine-phosphorylation of tubulin during monocytic differentiation of HL-60 cells. J. Immunol., 150: 585-593.

Kawakatsu, H., Sakai, T., Takagaki, Y., Shinoda, Y., Saito, M., Owada, M. K., and Yano, J. 1996. A new monoclonal antibody which selectively recognizes the active form of src tyrosine kinase. J. Biol. Chem., 271: 5680-5685.

Kinch, M.S., Clark, G.J., Der, C.J., and Burridge, K. 1995. Tyrosine phosphorylation regulates the adhesions of ras-transformed breast epithelia. J. Cell. Biol., 130: 461-471.

Kitajima, Y., Inoue, S., and Yaoita, H. 1986. Effects of pemphigus antibody on the organization of microtubules and keratin-intermediate filaments in cultured human keratinocytes. Br. J. Dermatol., 114: 171-179.

Kitajima, Y., Inoue, S., and Yaoita, H. 1987. Effects of pemphigus antibody on the regeneration of cell-cell contact in keratinocyte cultures grown in low to normal $\mathrm{Ca}^{++}$concentration. J. Invest. Dermatol., 89: 167-171.

Krueger, J., Zhao, Y.H., Murphy, D., and Sudol, M. 1991. Differential expression of p62c-yes in normal, hyperplastic and neoplastic human epidermis. Oncogene, 6: 933-940.

LaVallee, T.M., Prudovsky, I.A., McMahon, G.A., Hu, X., and Maciag, T. 1998. Activation of the MAP kinase pathway by FGF-1 correlates with cell proliferation induction while activation of the Src pathway correlates with migration. J. Cell Biol., 141: 1647-1658.

Levy, B.T., Sorge, L.K., Meymandi, A., and Maness, P.F. 1984. pp60c-src Kinase is in chick and human embryonic tissues. Dev. Biol., 104: 9-17.

Loeb, D.M., Woolford, J., and Beemon, K. 1987. pp60c-src has less affin- ity for the detergent-insoluble cellular matrix than do pp60v-src and other viral protein-tyrosine kinases. J. Virol., 61: 2420-2427.

Luttrell, L.M., Ferguson, S.S., Daaka, Y., Miller, W.E., Maudsley, S., Della Rocca, G.J., Lin, F., Kawakatsu, H., Owada, K., Luttrell, D.K., Caron, M.G., and Lefkowitz, R.J. 1999. Beta-arrestin-dependent formation of beta 2 adrenergic receptor-Src protein kinase complexes. Science, 283: 655-661.

Marie-Cardine, A., Kirchgessner, H., Eckerskorn, C., Meuer, S.C., and Schraven, B. 1995. Human T lymphocyte activation induces tyrosine phosphorylation of alpha-tubulin and its association with the SH2 domain of the p59fyn protein tyrosine kinase. Eur. J. Immunol., 25: 32903297.

Matsuyoshi, N., Hamaguchi, M., Taniguchi, S., Nagafuchi, A., Tsukita, S., and Takeichi, M. 1992. Cadherin-mediated cell-cell adhesion is perturbed by v-src tyrosine phosphorylation in metastatic fibroblasts. J. Cell Biol., 118: 703-714.

Miller, J.R. and Moon, R.T. 1996. Signal transduction through $\beta$-catenin and specification of cell fate during embryogenesis. Genes Dev., 10: 2527-2539.

Mureebe, L., Nelson, P.R., Yamamura, S., Lawitts, J., and Kent, K.C. 1997. Activation of pp60c-src is necessary for human vascular smooth muscle cell migration. Surgery, 122: 138-144; discussion 144-145.

Nakamura, N., Mishima, H., Nishida, T., and Otori, T. 1991. Requirement of microtubule assembly for initiation of EGF-stimulated corneal epithelial migration. Jpn. J. Ophthalmol., 35: 377-385.

Papkoff, J. 1997. Regulation of complexed and free catenin pools by distinct mechanisms. Differential effects of Wnt-1 and v-Src. J. Biol. Chem., 272: 4536-4543.

Resh, M.D. and Erikson, R.L. 1985. Highly specific antibody to Rous sarcoma virus src gene product recognize a novel population of pp60v-src and pp60c-src molecules. J. Cell Biol., 100: 409-417.

Reynolds, A.B., Herbert, L., Cleveland, J.L., Berg, S.T., and Gaut, J.R. 1992. p120, a novel substrate of protein tyrosine kinase receptors and of p60v-src, is related to cadherin-binding factors $\beta$-catenin, plakoglobin and armadillo. Oncogene, 7: 2439-2445.

Reynolds, A.B., Daniel, J., McCrea, P.D., Wheelock, M.J., Wu, J., and Zhang, Z. 1994. Identification of a new catenin: the tyrosine kinase substrate p120cas associates with E-cadherin complexes. Mol. Cell Biol., 14: 8333-8342.

Reynolds, A.B., Daniel, J.M., Mo, Y.Y., Wu, J., and Zhang, Z. 1996. The novel catenin p120cas binds classical cadherins and induces an unusual morphological phenotype in NIH3T3 fibroblasts. Exp. Cell Res., 225: 328-337.

Sakai, T., Kawakatsu, H., Fujita, M., Yano, J., and Owada, M.K. 1998. An epitope localized in c-Src negative regulatory domain is a potential marker in early stage of colonic neoplasms. Lab. Invest., 78: 219-225.

Shiraishi, T., Domoto, T., Imai, N., Shimada, Y., and Watanabe, K. 1987. Specific inhibitors of tyrosine-specific protein kinase, synthetic 4-hydroxycinnamamide derivatives. Biochem. Biophys. Res. Commun., 147: 322-328.

Shiraishi, T., Owada, M.K., Tatsuka, M., Yamashita, T., Watanabe, K., and Kakunaga, T. 1989. Specific inhibitors of tyrosine-specific protein kinases: properties of 4-hydroxycinnamamide derivatives in vitro. Cancer Res., 49: 2374-2378.

Shiraishi, T., Owada, M.K., Tatsuka, M., Fuse, Y., Watanabe, K., and Kakunaga, T. 1990. A tyrosine-specific protein kinase inhibitor, alphacyano-3-ethoxy-4-hydroxy-5-phenylthiomethylcinnamamide, blocks the phosphorylation of tyrosine kinase substrate in intact cells. Jpn. J. Cancer Res., 81: 645-652.

Takeichi, M. 1991. Cadherin cell adhesion receptors as a morphogenetic regulator. Science, 251: 1451-1455.

Tsukita, S., Tsukita, S., Nagafuchi, A., and Yonemura, S. 1992. Molecular linkage between cadherins and actin filaments in cell-cell adherens junc- 
tions. Current Opinion in Cell Biol., 4: 834-839.

Weissman, B. and Aaronson, S.A. 1985. Members of the src and ras oncogene families supplant the epidermal growth factor requirement of BALB/MK-2 keratinocytes and induce distinct alterations in their terminal differentiation program. Mol. Cell Biol., 5: 3386-3396.

Willingham, M.C., Jay, G., and Pastan, I. 1979. Localization of avian sarcoma virus src gene product to the plasma membrane of transformed cells by electron microscopic immunocytochemistry. Cell, 18: 125-134. Zhao, Y., Sudol, M., Hanafusa, H., and Krueger, J. 1992. Increased tyrosine kinase activity of c-Src during calcium-induced keratinocyte differentiation. Proc. Natl. Acad. Sci. USA, 89: 8298-8302.

(Received for publication, September 29, 2000

and in revised form, December 27, 2000) 